\title{
Article
}

\section{Integer Search Algorithm: A New Discrete Multi-Objective Algorithm for Pavement Maintenance Management Optimization}

\author{
Abdulraaof Alqaili ${ }^{1, *(\mathbb{D}}$, Mohammed Qais ${ }^{2, *}$ and Abdullah Al-Mansour ${ }^{1}$ \\ 1 Civil Engineering Department, Faculty of Engineering, King Saud University, Riyadh 11421, Saudi Arabia; \\ amansour@ksu.edu.sa \\ 2 Electrical Engineering Department, Faculty of Engineering, King Saud University, Riyadh 11421, Saudi Arabia \\ * Correspondence: aalqaili@ksu.edu.sa (A.A.); mqais@ksu.edu.sa (M.Q.)
}

Citation: Alqaili, A.; Qais, M.; Al-Mansour, A. Integer Search Algorithm: A New Discrete Multi-Objective Algorithm for Pavement Maintenance Management Optimization. Appl. Sci. 2021, 11, 7170. https://doi.org/10.3390/ app11157170

Academic Editor: Peng-Yeng Yin

Received: 23 June 2021

Accepted: 29 July 2021

Published: 3 August 2021

Publisher's Note: MDPI stays neutral with regard to jurisdictional claims in published maps and institutional affiliations.

Copyright: () 2021 by the authors. Licensee MDPI, Basel, Switzerland. This article is an open access article distributed under the terms and conditions of the Creative Commons Attribution (CC BY) license (https:// creativecommons.org/licenses/by/ $4.0 /)$.

\begin{abstract}
Optimization techniques keep road performance at a good level using a cost-effective maintenance strategy. Thus, the trade-off between cost and road performance is a multi-objective function. This paper offers a new multi-objective stochastic algorithm for discrete variables, which is called the integer search algorithm (ISA). This algorithm is applied to an optimal pavement maintenance management system (PMMS), where the variables are discrete. The PMMS optimization can be achieved by maximizing the condition of pavement with a minimum cost at specified constraints, so the PMMS is a constrained multi-objective problem. The ISA and genetic algorithm (GA) are applied to improve the performance condition rating (PCR) of the pavement in developing countries, where the annual budget is limited, so a minimum cost for three years' maintenance is scheduled. Study results revealed that the ISA produced an optimal solution for multi-function objectives better than the optimal solution of GA.
\end{abstract}

Keywords: genetic algorithm; integer search algorithm; pavement maintenance management

\section{Introduction}

Roadways are considered the arteries of economic and social activities at the national and local levels. Furthermore, they are one of the fundamental foundations of development countries. Pavement is an essential component of road infrastructure. Its surface plays an important role in providing a safe and comfortable environment for users. During the pavement design life, the pavement is exposed to increasing traffic volumes with heavy loads, environmental adverse impacts, and poor use, which lead to significant deterioration of the pavement. To make the pavement function better, regular maintenance should be done to repair the degradation of the pavement. Therefore, through regular maintenance, a sufficient budget will be spent to maintain the pavement at an adequate condition. Actually, limited budgets are the biggest difficulties and challenges facing the pavement maintenance. For this reason, the pavement maintenance activities should be managed within the available budget and resources [1]. A good pavement management program will preserve the condition of all road sections at an adequate high performance with minimum cost without any reverse effects on traffic operation, environment, or social activity [2]. Therefore, decision-makers need to have the methodologies for maintenance management to attain a sufficient level of service at a minimum cost [3]. In other words, optimizing the available budget allocation is needed for decision-makers to assist them in achieving the specified objectives of pavement performance under available budget and authority constraints [4].

Initially, the priority (rank) was used to determine pavement treatment plans. When the priority is applied, the maintenance activities (alternatives) are allocated using a ranking system based on parameters such as traffic volume, road class, quality index, etc. These parameters are determined based on road condition data for the current year. Therefore, the best maintenance plan cannot be assured by using a prioritization approach, and multi-year 
planning will also be problematic. In the last few decades, the optimization approach has been a priority to create the best possible solution for pavement maintenance strategy. In early maintenance optimization, the decision-making process was based on singleobjective optimization. However, the decision-making process in pavement maintenance involves many objectives (e.g., cost, performance, etc.) that conflict with each other, and the solution resulting from single-objective optimization may be unacceptable to other objectives. Therefore, a reasonable solution to a multi-objective problem is to search for a set of solutions that satisfy the requirements of several objectives [5].

The programming methods, such as stochastic and deterministic, are utilized to satisfy the constraints related to the requirements of the road network for the proper maintenance plan. Stochastic techniques (e.g., Markov chain) are useful for the insufficient data of pavement conditions [6]. While, a set of deterministic techniques were used to resolve maintenance problems, such as dynamic programming [7], goal programming [8], quadratic programming framework [9], and nonlinear mathematical program [10].

Many methods are used for multi-objective optimizations, such as the weighted sum method, which is used widely. By this approach, several objective functions are summated with suitable weight for each objective function. The criteria are weighted, and the comparison of sorting orders is made for outcome reliability [11]. The priority process is divided into two stages: defining maintenance activities, and then analysis of trade-offs is executed to introduce many prioritized activities [12]. The multi-criteria are generated and weighted to specify the assets of prioritization [13].

By using the theory of multi-attribute utility, an axiomatizing mathematical process is suggested to quantify and analyze the alternatives, which include many competing results [14-16]. This method is a good trial to link the objectives of maintenance treatments on asphalt pavements and define the choices of decision-making. On the other hand, the analytic hierarchy process to estimate the weights of criteria set and alternatives are used [17-20]. In this regard, the other options are compared with related standards set by using pair-wise comparisons, then the criteria weight is determined. Thus, hierarchically, the alternatives and criteria are formed.

The genetic algorithm (GA) is an evolutionary computation technique, which is widely applied to solve different objectives of maintenance problems. The ability of a genetic algorithm in the optimization process is to deal with either simple issues (e.g., linear optimization) or the complex computational problems (e.g., multimodality) and support decision-making procedure with a reasonable solution in the maintenance plan. For this reason, GA has been used widely in maintenance optimization. GA technique provides a solution for allocation the available funds to achieve the objectives constrained of the resource of central and regional agencies [21]. Also, the GA is utilized to address the nature of combinatorial maintenance programing in the network-level of roads [22]. Besides, GA is applied to attain optimum maintenance plans at sufficient level for pavement sections [22]. For constrained optimization, the GA is used to optimize the maintenance of rural roads network by minimizing cost and maximizing the road performance [23-25]. An adaptive hybrid GA, which contains GA and local search, is applied for improving the effectiveness and efficiency of solution searching for the optimal maintenance plan [26].

Also, discrete particle swarm optimization (PSO) is applied to optimize a multiobjective problem for pavement maintenance optimization. In this method, random solutions are created, and optimal searching is made by updating populations [27,28]. Additionally, a parameter-free velocity term is introduced to the barebones algorithm, which can provide a feasible decision-making process [29].

Dominance-based rough set approach is mainly used in the selection of the best solution when a large number of the possible solutions has existed. In other words, this method enhances the decision-making process for optimizing various maintenance activities to accomplish predefined objectives and make optimal allocation of the available budget. In this method, the rough set theory is used, making it possible to analyze the contradiction. The optimization is achieved by this method through two stages. In 
the first one, a set of solutions from the Pareto optimal is created. In the second one, through the decision-making process, the best solutions in the created set are indicated $[30,31]$. The interactive multi-objective optimization-dominance rough set approach is also used to support decision-making interaction to determine the optimal set of maintenance activities [32].

However, most of the metaheuristic optimization algorithms are based on the real random numbers, which are not suitable for the discrete problems. This paper presented a new discrete algorithm called integer search algorithm (ISA) to optimize the PMMS problem. To continue in searching for methods to find the optimal solution supporting the decision making of pavement maintenance, this paper presents a new discrete stochastic algorithm called integer search algorithm (ISA) for the pavement management system. Also, the ISA and GA are applied to improve the pavement management for the road networks in a developing country with a limited annual budget. Furthermore, the convergence curves of ISA and GA during the optimization process are compared.

\section{Pavement Maintenance Model}

\subsection{Pavement Condition Evaluation}

The state of the pavement plays a significant role in the decision-making process for pavement repair. The pavement repair activities are dependent on the current condition of the pavement. As a result, determining the best maintenance strategy necessitates assessing the state of the pavement. In order to describe the current pavement condition, the proposed study used the pavement condition rating (PCR) with the grading system from 0 (Failed) to 4 (Excellent) as presented in Table 1.

Table 1. Pavement condition rating for IRI

\begin{tabular}{ccc}
\hline PCR & IRI (m/km) & Condition Description \\
\hline 0 & $>10$ & Failed: out of service \\
\hline 1 & $(6,10]$ & Poor condition: foremost maintenance is required \\
\hline 2 & {$[4,6]$} & Fair condition: medium maintenance is required \\
\hline 3 & {$[2,4)$} & Good condition: less maintenance is required \\
\hline 4 & $<2$ & Excellent condition: maintenance is not required \\
\hline
\end{tabular}

\subsection{Pavement Preservation Treatments}

Pavement treatments are selected based on the purpose of the maintenance strategies of the networks. For retarding the pavement deterioration and reducing the distresses, this study interested on preventive maintenance treatments. Five maintenance activities were used in this study to implement the pavement maintenance called do nothing, crack seal, slurry seal, thin asphalt overlay, and thick asphalt overlay. These activities are assigned codes which are M-00, M-01, M-02, M-03, and M-04, respectively.

\subsection{Performance Jumps}

Application of pavement preservation treatments on the pavement surface leads to improve the pavement condition. The effectiveness of preservation treatments occurs in the performance improvement after the performing treatments. Therefore, the treatment effects should be determined to know the pavement condition after the treatments application by defining the performance jumps. This study used the performance jumps developed by Morcous and Lounis [24] as shown in Table 2. 
Table 2. Influence of repair decisions on PCR

\begin{tabular}{ccccccc}
\hline \multirow{2}{*}{ PCR } & & \multicolumn{4}{c}{ PCR after Maintenance } \\
\cline { 2 - 6 } & & $\mathbf{1}$ & $\mathbf{2}$ & $\mathbf{3}$ & $\mathbf{4}$ \\
\hline \multirow{3}{*}{$\begin{array}{c}\text { PCR before } \\
\text { maintenance }\end{array}$} & 0 & $\mathrm{M}-01$ & $\mathrm{M}-02$ & $\mathrm{M}-03$ & $\mathrm{M}-04$ \\
\cline { 2 - 6 } & 1 & - & $\mathrm{M}-01$ & $\mathrm{M}-02$ & $\mathrm{M}-03$ \\
\cline { 2 - 6 } & 2 & - & - & $\mathrm{M}-01$ & $\mathrm{M}-02$ \\
\cline { 2 - 6 } & 3 & - & - & - & $\mathrm{M}-01$ \\
\hline
\end{tabular}

\section{Optimization Methodology}

The PMMS is a discrete problem, where the input variables are the maintenance activities, which are integer numbers between $[0,4]$. Also, the output variables are the PCR of pavement, which are integer numbers between [0,4]. Most of the metaheuristic optimization calculations are based on the real numbers, which are not reasonable for the PMMS issue. Thus, this paper displayed a modern discrete calculation called integer search algorithm (ISA) to optimize the PMMS problem.

\subsection{Integer Search Algorithm}

Most of the stochastic algorithms are based on the real numbers, which are used in all engineering applications. However, the variables of the PMMS problem are integer numbers, where these stochastic algorithms need adaptation to be suitable for discrete problems. Therefore, this paper has proposed a new discrete algorithm suitable for the discrete problem, which is called integer search algorithm (ISA). The ISA algorithm is proposed based on the random generation of integer numbers. The exploration and exploitation of the ISA algorithm are controlled using parameters a and A, as in (1) and (2). The ISA algorithm updates the integer variables $X(i)$, as in (3). The main merits of the ISA algorithm are simplicity and speed.

$$
\begin{gathered}
a=\text { round }\left(b-b \times \frac{\text { Iter }}{\text { Max_iter }}\right) \\
A=\text { Integer Random } \in[-1,1] \times a \\
X(i)=X_{\text {best }}(i)+A
\end{gathered}
$$

where $b$ is a constant $\geq 2, X_{b e s t}(i)$ is the best position of variable $X(i)$, Iter is the iteration number, and Max_iter is the maximum number of iterations. the flowchart of the ISA algorithm is depicted in Figure 1.

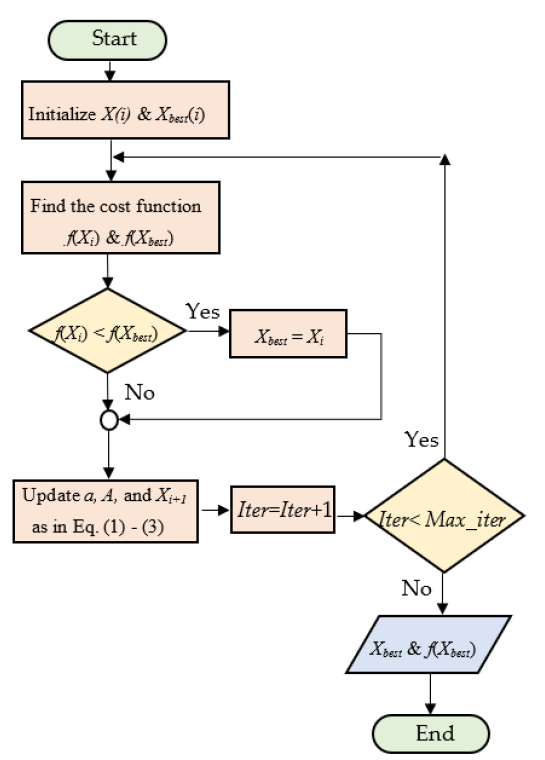

Figure 1. Flowchart of the integer search algorithm. 


\subsection{Objective Function}

The optimization model formulation is performed in a way for keeping the level of the road performance at an acceptable level by using strategies of cost-effective maintenance. This constitutes using a multi-objective function in decision making to obtain the optimal maintenance plan.

As aforementioned, the PCR was used to evaluate the pavement condition in this study then one of the objective functions is maximizing the PCR value as shown in Equation (4). The other function is minimizing the cost to attain the optimal solution with minimum cost as possible as shown in Equation (5). In this study, the establishment of pavement maintenance strategies were constrained by the available budget for maintenance and the desired level of performance. The annual budget $B t$ constrains the objective function as in Equation (6). The Equation (7) is the constraint of the pavement performance. Only applying of one treatment is taken into account for each road section in each year as in Equation (8).

$$
\begin{aligned}
& \operatorname{Max} \sum_{S=1}^{S} \sum_{j=1}^{m} P C R_{s, t}\left(X_{s, j}\right) \\
& \operatorname{Min} \sum_{S=1}^{S} \sum_{j=1}^{m} C\left(X_{s, j}\right) L_{S} W_{S}
\end{aligned}
$$

Subjected to

$$
\begin{array}{cl}
\sum_{s=1}^{S} C\left(X_{s, j}\right) \times L_{s} \times W_{s} \leq B_{t}, & \forall s=1 \text { to } S \\
\sum_{s=1}^{S} C\left(X_{s, j}\right) \times L_{s} \times W_{s} \leq B_{t}, & \forall s=1 \text { to } S \\
\sum_{j=1}^{m} X_{s, j}=1, & \forall s=1 \text { to } S
\end{array}
$$

where, $X_{s, j}$ maintenance application (option) for section $s$ and treatment $j, C$ is the cost of maintenance activity, $L_{s}$, and $W_{s}$ are the length and width of the roadway section. The total maintenance cost of all sections is calculated as in (6).

\subsection{Genetic Algorithm}

The genetic algorithm (GA) is an evolutionary metaheuristic algorithm that has been applied to many engineering disciplines $[33,34]$. GAs work with a population of entities denoted by bit strings and change the population with random exploration and competition. In general, GAs consist of trials, for example, selection, crossover, and mutation. Generation is a procedure in which a novel cluster of entities is made by choosing the proper entities in the existing population. Crossover is the greatest influential worker in GAs. It constructs novel children by choosing two strings and exchange segments of their structures. The novel children may exchange the worst entities in the population. The mutation is a local worker with a very low likelihood, where its purpose is to adjust the value of a random position in a string.

In this work, the population of the GA algorithm is 100, where the population are initialized randomly. After that, this generated population is reproduced using crossover and mutation, where the crossover probability is set to $80 \%$ and the mutation probability is set to 0.05 .

\subsection{Optimization Procedure}

The ISA algorithm is applied to find the optimal solution of the constrained multiobjective function shown in (4) and (5). The input variable is the maintenance activity 
$\left(X_{M A}(s, j)\right)$ performed for each road section $s$ and for treatment $j$. then the PCR of each section in a specific year is updated as in (9). The initialization of PCR, according to the constraints, is shown in the pseudo-code in Figure 2. The optimization procedure is applied for a number of sections and for a specified number of years, as shown in the pseudo-code in Figure 3.

$$
\operatorname{PCR}(s, t)=\operatorname{PCR}(s, t-1)+X_{M A}(s, t)
$$

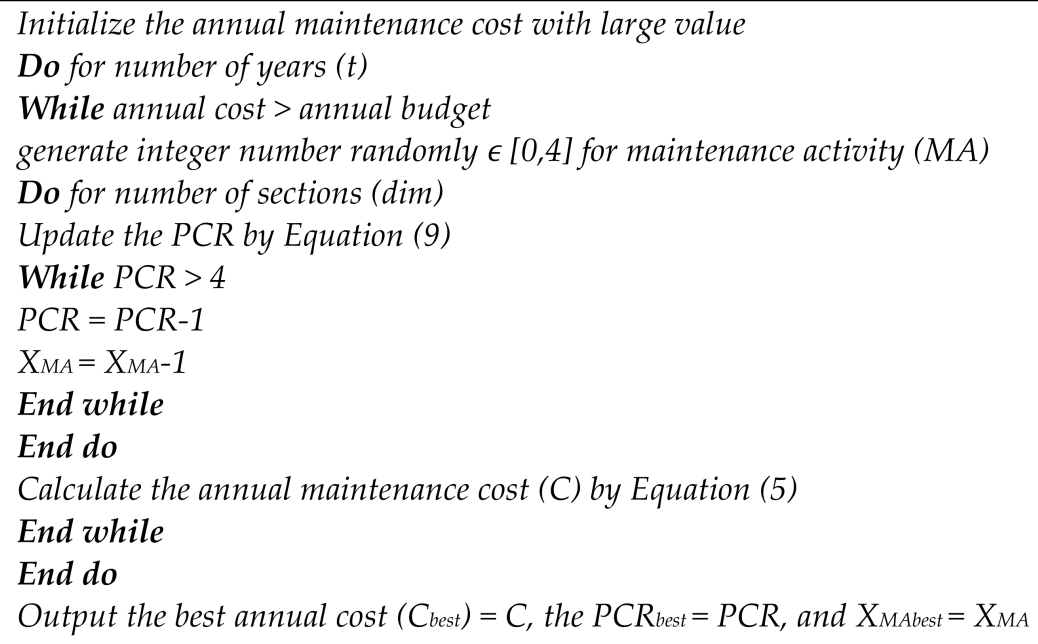

Figure 2. Pseudo-code of PCR initialization.

Initialize the best annual cost, best PCR, and best MA from Algorithm 1

While iterations < maximum number of iterations

Calculate a by Equation (1)

Do for number of years ( $t$ )

Do for number of sections (dim)

Calculate A by Equation (2)

Calculate $X_{M A}$ by Equation (3)

Update the PCR by Equation (9)

While PCR $>4$

$P C R=P C R-1$

$X_{M A}=X_{M A}-1$

End while

End Do

Calculate the annual maintenance cost (C) by Equation (5)

End Do

If the $C$ less than $C_{a-b e s t}$ and the sum of PCR less than PCRbest then

$C_{\text {best }}=C$, the $P C R_{\text {best }}=P C R$, and $X_{M A b e s} t=X_{M A}$

End if

End while

Figure 3. Pseudo-code of the application of the ISA algorithm for PMMS problem.

\section{Case Study}

The applicability of proposed algorithm was demonstrated by performing a case study. The data of the case study was obtained from the General Corporation of Roads and Bridges, Hajjah, Yemen, which is classified as a developing country. Roadway network contains 16 roads comprises arterial, main, and local access roads; which include 49 sections with $23 \mathrm{~km}$ total length. Code, length, width, and initial PCR for each road section are 
presented in Table 3. Annually, the maintenance activities are implemented within a specified available budget of around $\$ 80,000$ based on the agency constraints. This study adopts a medium-term planning time horizon of three-year (2020-2022) to develop the pavement maintenance program. Maintenance costs related to repair decisions were collected from the General Corporation of Roads and Bridges in Yemen as 0.6, 1.08, 2.09, and $3\left(\$ / \mathrm{m}^{2}\right)$ for crack seal, slurry seal, thin asphalt overlay, and thick asphalt overlay, respectively.

Table 3. Road sections condition data

\begin{tabular}{|c|c|c|c|c|c|c|c|c|c|}
\hline$\#$ & Street Name & Road Class & $\begin{array}{c}\text { Section } \\
\text { Code }\end{array}$ & $\begin{array}{l}\text { Length } \\
\text { (m) }\end{array}$ & $\begin{array}{l}\text { Width } \\
\text { (m) }\end{array}$ & $\begin{array}{l}\text { Area } \\
\left(\mathrm{m}^{2}\right)\end{array}$ & IRI & $\begin{array}{c}\text { Road } \\
\text { Condition }\end{array}$ & PCR \\
\hline 1 & Sana'a Road & Arterial & 1R/100 & 92 & 7.1 & 656 & 5 & Fair & 2 \\
\hline 2 & Sana'a Road & Arterial & 1L/100 & 243 & 7.1 & 1725 & 4 & Fair & 2 \\
\hline 3 & Sana'a Road & Arterial & $2 \mathrm{R} / 100$ & 172 & 7.1 & 1221 & 6 & Fair & 2 \\
\hline 4 & Sana'a Road & Arterial & $3 / 100$ & 449 & 8 & 3592 & 7 & Poor & 1 \\
\hline 5 & Sana'a Road & Arterial & $4 / 100$ & 574 & 8 & 4592 & 12 & Bad & 0 \\
\hline 6 & Sana'a Road & Arterial & $5 / 100$ & 528 & 8 & 4224 & 11 & Bad & 0 \\
\hline 7 & Sana'a Road & Arterial & $6 / 100$ & 426 & 8 & 3408 & 13 & Bad & 0 \\
\hline 8 & Sana'a Road & Arterial & $7 / 100$ & 491 & 8 & 3928 & 8 & Poor & 1 \\
\hline 9 & Sana'a Road & Arterial & $8 / 100$ & 627 & 8 & 5016 & 9 & Poor & 1 \\
\hline 10 & Sana'a Road & Arterial & $9 / 100$ & 586 & 8 & 4688 & 13 & Bad & 0 \\
\hline 11 & Al-Hodaidah & Arterial & $1 \mathrm{R} / 200$ & 211 & 5 & 1055 & 6 & Fair & 2 \\
\hline 12 & Al-Hodaidah & Arterial & $1 \mathrm{~L} / 200$ & 396 & 5 & 1980 & 3 & Good & 3 \\
\hline 13 & Al-Hodaidah & Arterial & $2 \mathrm{R} / 200$ & 521 & 5 & 2605 & 5 & Fair & 2 \\
\hline 14 & Al-Hodaidah & Arterial & $2 \mathrm{~L} / 200$ & 875 & 5 & 4375 & 6 & Fair & 2 \\
\hline 15 & Al-Hodaidah & Arterial & $3 R / 200$ & 540 & 5 & 2700 & 5 & Fair & 2 \\
\hline 16 & Al-Hodaidah & Arterial & $4 / 200$ & 602 & 7 & 4214 & 3 & Good & 3 \\
\hline 17 & Al-Souq & Main & $1 / 110$ & 163 & 7 & 1141 & 7 & Poor & 1 \\
\hline 18 & Al-Souq & Main & $2 / 110$ & 238 & 7 & 1666 & 9 & Poor & 1 \\
\hline 19 & Al-Souq & Main & $3 / 110$ & 116 & 7 & 812 & 8 & Poor & 1 \\
\hline 20 & Al-Souq & Main & $4 / 110$ & 105 & 7 & 735 & 7 & Poor & 1 \\
\hline 21 & Al-Souq & Main & $5 / 110$ & 127 & 7 & 889 & 10 & Poor & 1 \\
\hline 22 & Al-Souq & Main & $6 / 110$ & 251 & 7 & 1757 & 6 & Fair & 2 \\
\hline 23 & Al-Dahreen & Main & $1 / 120$ & 285 & 7.2 & 2052 & 8 & Poor & 1 \\
\hline 24 & Al-Dahreen & Main & $2 / 120$ & 82 & 7.2 & 591 & 8 & Poor & 1 \\
\hline 25 & Al-Dahreen & Main & $3 / 120$ & 319 & 7.2 & 2297 & 6 & Fair & 2 \\
\hline 26 & Al-Dahreen & Main & $4 / 120$ & 276 & 7.2 & 1987 & 6 & Fair & 2 \\
\hline 27 & Al-Dahreen & Main & $5 / 120$ & 562 & 7.2 & 4046 & 9 & Poor & 1 \\
\hline 28 & Al-Dahreen & Main & $6 / 120$ & 107 & 7.2 & 770 & 9 & Poor & 1 \\
\hline 29 & Al-Dahreen & Main & $7 / 120$ & 586 & 7.2 & 4219 & 10 & Poor & 1 \\
\hline 30 & Al-Nasieryah & Local Access & $1 / 116$ & 694 & 8 & 5552 & 3 & Good & 3 \\
\hline 31 & Al-Qahirah & Local Access & $1 / 112$ & 329 & 6.5 & 2139 & 11 & Bad & 0 \\
\hline 32 & Al-Mohandis & Main & $1 / 150$ & 1348 & 6.3 & 8492 & 3 & Good & 3 \\
\hline 33 & Al-Mahjan & Main & $1 / 130$ & 567 & 7 & 3969 & 9 & Poor & 1 \\
\hline 34 & Al-Mahjan & Main & $2 / 130$ & 1028 & 7 & 7196 & 5 & Fair & 2 \\
\hline 35 & Qarn Habab & Main & $1 / 160$ & 156 & 6.1 & 952 & 13 & Bad & 0 \\
\hline 36 & Qarn Habab & Main & $2 / 160$ & 489 & 6.1 & 2983 & 11 & Bad & 0 \\
\hline 37 & Qarn Habab & Main & $3 / 160$ & 169 & 6.1 & 1031 & 12 & Bad & 0 \\
\hline 38 & Qarn Habab & Main & $4 / 160$ & 93 & 6.1 & 567 & 10 & Poor & 1 \\
\hline 39 & Na'aman & Local Access & $1 / 113$ & 725 & 6 & 4350 & 10 & Poor & 1 \\
\hline 40 & Al-Helah & Main & $1 / 170$ & 140 & 7.2 & 1008 & 7 & Poor & 1 \\
\hline 41 & Al-Helah & Main & $2 / 170$ & 307 & 7.2 & 2210 & 9 & Poor & 1 \\
\hline 42 & Al-Helah & Main & $3 / 170$ & 427 & 7.2 & 3074 & 8 & Poor & 1 \\
\hline 43 & Haorah & Local Access & $1 / 111$ & 761 & 8 & 6088 & 2 & Good & 3 \\
\hline 44 & Haorah & Local Access & $2 / 111$ & 352 & 8 & 2816 & 7 & Poor & 1 \\
\hline 45 & Al-Gharabi & Main & $1 / 180$ & 1401 & 7.1 & 9947 & 8 & Poor & 1 \\
\hline 46 & Al-Gharabi & Main & $2 / 180$ & 1926 & 7.1 & 13675 & 9 & Poor & 1 \\
\hline 47 & Al-Ma'enah & Main & $1 / 140$ & 889 & 7 & 6223 & 10 & Poor & 1 \\
\hline 48 & Dhola'ah & Local Access & $1 / 114$ & 315 & 6.1 & 1922 & 12 & Bad & 0 \\
\hline 49 & Qirwee & Local Access & $1 / 115$ & 431 & 4 & 1724 & 11 & Bad & 0 \\
\hline
\end{tabular}

\section{Results and Discussion}

The ISA and GA algorithms are applied to maximize the total PCR of all road sections for three years and, at the same time, minimize the total cost of pavement maintenance. The PMMS model and ISA and GA algorithms are coded using MATLAB 2019b. The 
population size of both algorithms is set to 100 , and the maximum number of iterations is set to 10,000 . Therefore, the number of function evaluations is $100 \times 10,000=1,000,000$. The optimization process is executed using PC (Intel (R) Core (TM) i7-3770 CPU @ $3.40 \mathrm{GHz}$ (8 CPUs), 16 GB, Windows 7-64 bits). Figure 4 shows that the attained cumulative PCR for 3 years and 49 sections using the ISA algorithm is 470 , which is larger than that achieved by GA (PCR $=466$ ). Furthermore, Figure 5 shows that the total cost of maximizing the PCR is minimized using ISA algorithm less than the total cost by using GA.

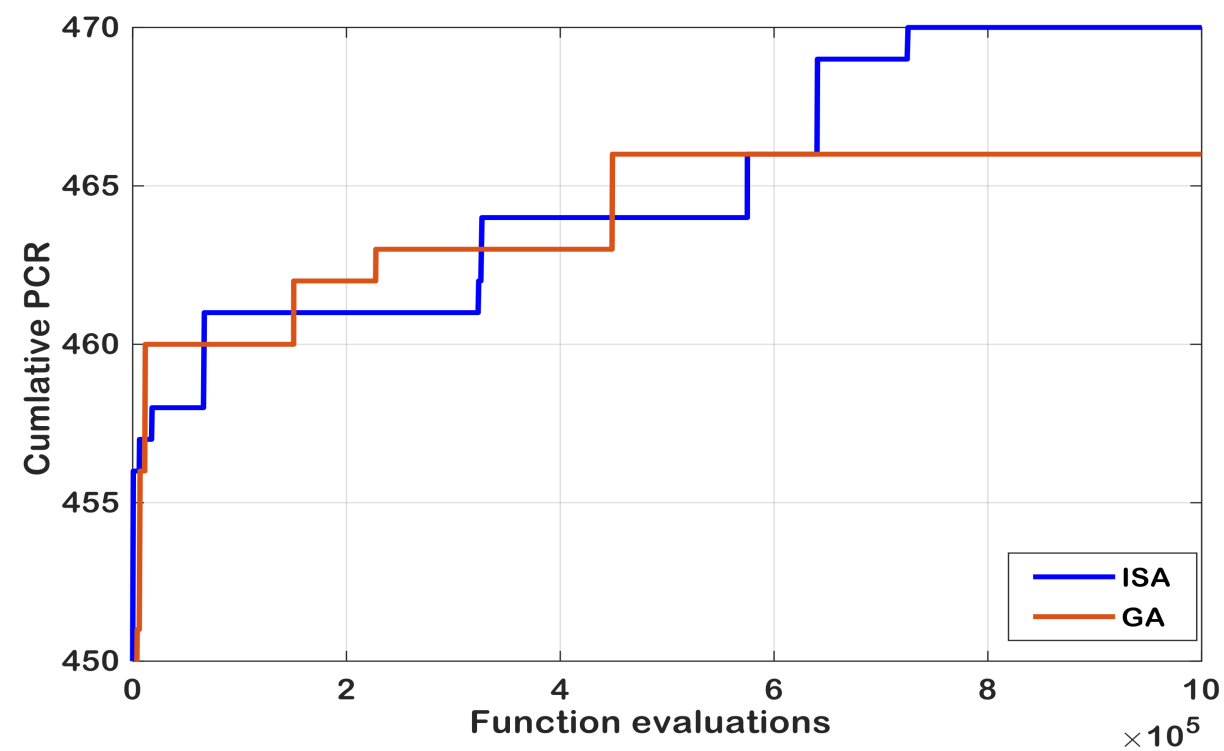

Figure 4. Convergence of the cumulative PCR for 3 years and 49 sections.

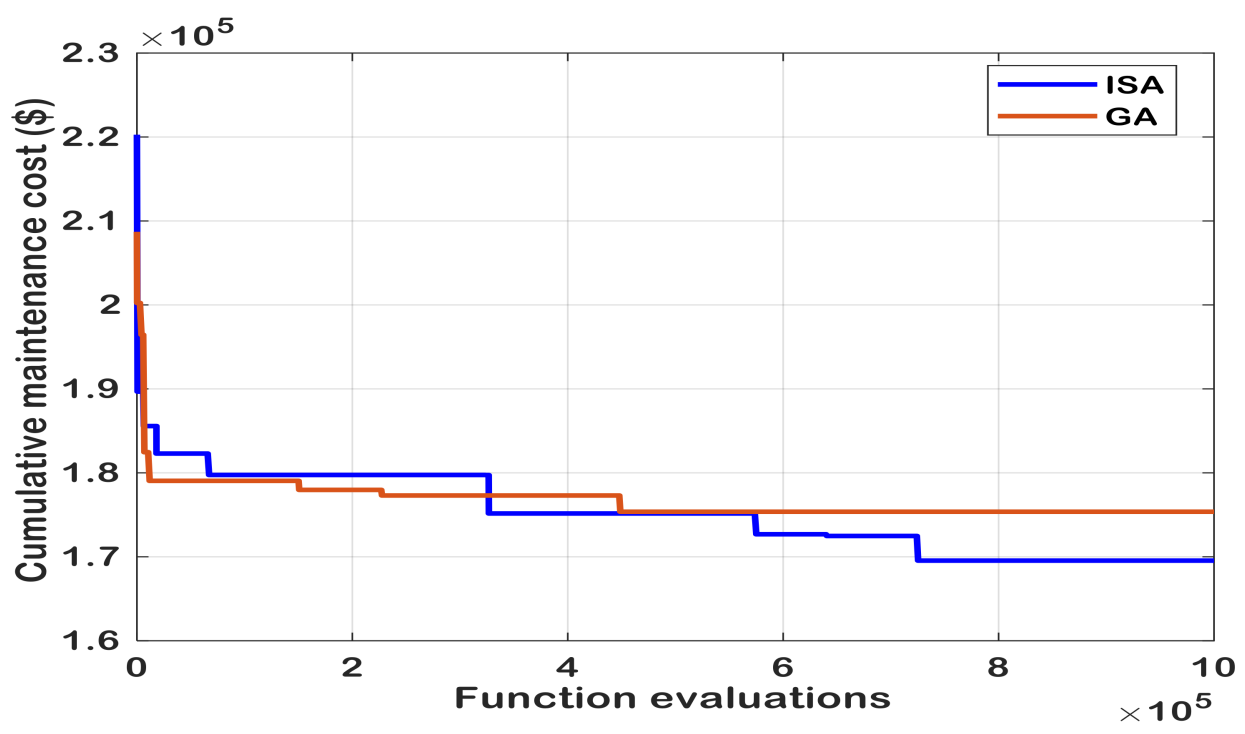

Figure 5. Convergence of the cumulative maintenance cost for 3 years and 49 sections.

Table 4 shows the optimal maintenance plan to attain acceptable performance within the available annual maintenance budget $(\$ 80,000)$. Therefore, the maintenance activities are distributed for all 49 sections for 3 years. For the first year $t=1$ and for Sana'a road that contains 10 sections (from 1 to 10), sections 2, 6, 5, and 10 are not maintained M-00 (blue colored). However, sections $1,4,7,8$, and 9 are maintained by the maintenance activity M-01 (yellow colored), and Section 3 is maintained by using M-02 (green colored). In the second year, sections 1 and 3 are not maintained (M-00). However, sections 2, 5, 8, and 9 are maintained by using M-01, and sections 4,6 , 7, and 10 are maintained by using M-02. 
Finally, in the third year, sections 2, 3, 4, and 7 are not maintained. However, sections 1, 5, $6,8,9$, and 10 are maintained by using M-01. The last column in Table 4 shows that the PCR of about 36 sections improved to rank 4 . However, 13 sections still need maintenance, which can be maintained in the third year because the total cost is low this year.

Table 4. Optimal maintenance activity plan by ISA algorithm to improve the pavement condition.

\begin{tabular}{|c|c|c|c|c|c|c|c|}
\hline \multirow{2}{*}{$\frac{\text { Section }}{\mathrm{s}}$} & \multicolumn{3}{|c|}{ Input Variables of ISA Algorithm } & \multirow{2}{*}{$\begin{array}{c}\text { Section } \\
s\end{array}$} & \multicolumn{3}{|c|}{ Input Variables of ISA Algorithm } \\
\hline & $X_{M A}(s, t=1)$ & $X_{M A}(s, t=2)$ & $X_{M A}(s, t=3)$ & & $X_{M A}(s, t=1)$ & $X_{M A}(s, t=2)$ & $X_{M A}(s, t=3)$ \\
\hline 1 & 1 & 0 & 1 & 26 & 2 & 0 & 0 \\
\hline 2 & 0 & 1 & 0 & 27 & 1 & 2 & 0 \\
\hline 3 & 2 & 0 & 0 & 28 & 3 & 0 & 0 \\
\hline 4 & 1 & 2 & 0 & 29 & 1 & 0 & 1 \\
\hline 5 & 0 & 1 & 1 & 30 & 0 & 1 & 0 \\
\hline 6 & 0 & 2 & 1 & 31 & 2 & 2 & 0 \\
\hline 7 & 1 & 2 & 0 & 32 & 0 & 0 & 0 \\
\hline 8 & 1 & 1 & 1 & 33 & 0 & 1 & 1 \\
\hline 9 & 1 & 1 & 1 & 34 & 0 & 0 & 0 \\
\hline 10 & 0 & 2 & 1 & 35 & 4 & 0 & 0 \\
\hline 11 & 2 & 0 & 0 & 36 & 2 & 1 & 0 \\
\hline 12 & 1 & 0 & 0 & 37 & 2 & 1 & 1 \\
\hline 13 & 2 & 0 & 0 & 38 & 3 & 0 & 0 \\
\hline 14 & 0 & 2 & 0 & 39 & 3 & 0 & 0 \\
\hline 15 & 2 & 0 & 0 & 40 & 3 & 0 & 0 \\
\hline 16 & 0 & 1 & 0 & 41 & 2 & 1 & 0 \\
\hline 17 & 3 & 0 & 0 & 42 & 0 & 3 & 0 \\
\hline 18 & 2 & 1 & 0 & 43 & 0 & 1 & 0 \\
\hline 19 & 3 & 0 & 0 & 44 & 0 & 3 & 0 \\
\hline 20 & 0 & 3 & 0 & 45 & 0 & 0 & 0 \\
\hline 21 & 3 & 0 & 0 & 46 & 0 & 0 & 0 \\
\hline 22 & 2 & 0 & 0 & 47 & 1 & 0 & 0 \\
\hline 23 & 2 & 0 & 1 & 48 & 2 & 2 & 0 \\
\hline 24 & 2 & 1 & 0 & 49 & 4 & 0 & 0 \\
\hline 25 & 2 & 0 & 0 & & & & \\
\hline
\end{tabular}

Figure 6 shows how the PCR is maximized by 193\% from 1.22 in 2019 to 3.59 in 2022. The PCR maximization is constrained with the predefined annual budget $(\$ 80,000)$ and $\$ 240,000$ for three years. Also, Figure 7 shows the annual maintenance cost for three years scheduled maintenance, where the average cost of three years is $\$ 56,515,446$. Table 5 displays the obtained optimal total cost using the ISA algorithm is $\$ 169,546.34$, where the cost-saving is about $29.4 \%$. However, the total cost using GA is about $\$ 178,000$, which is higher than the cost by using ISA. 


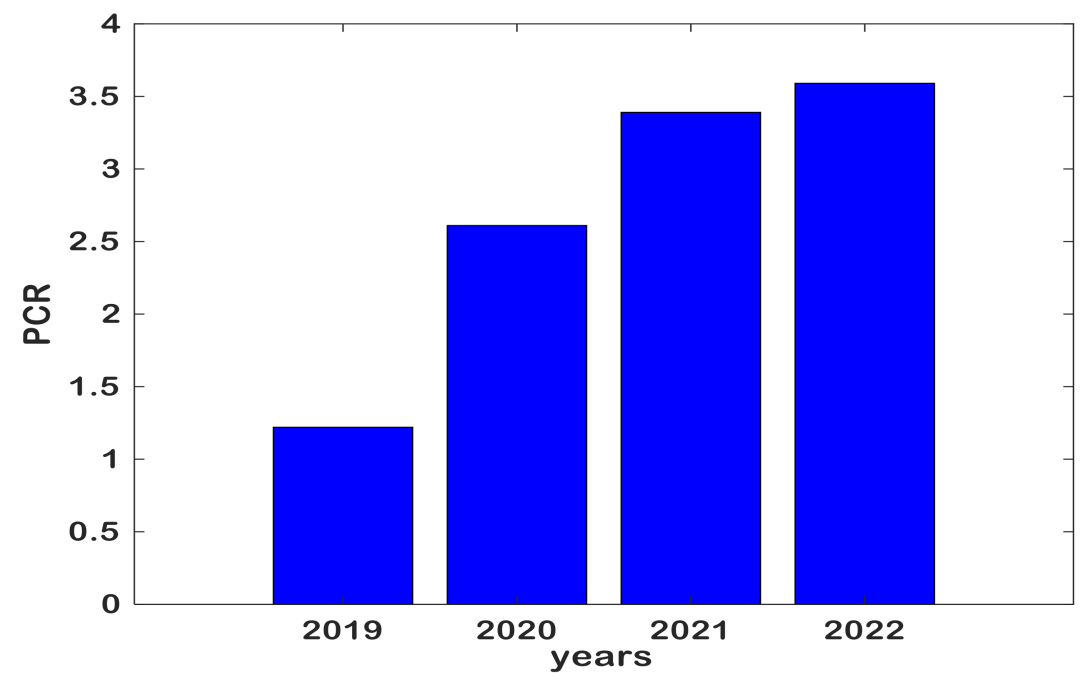

Figure 6. Improvement of PCR.

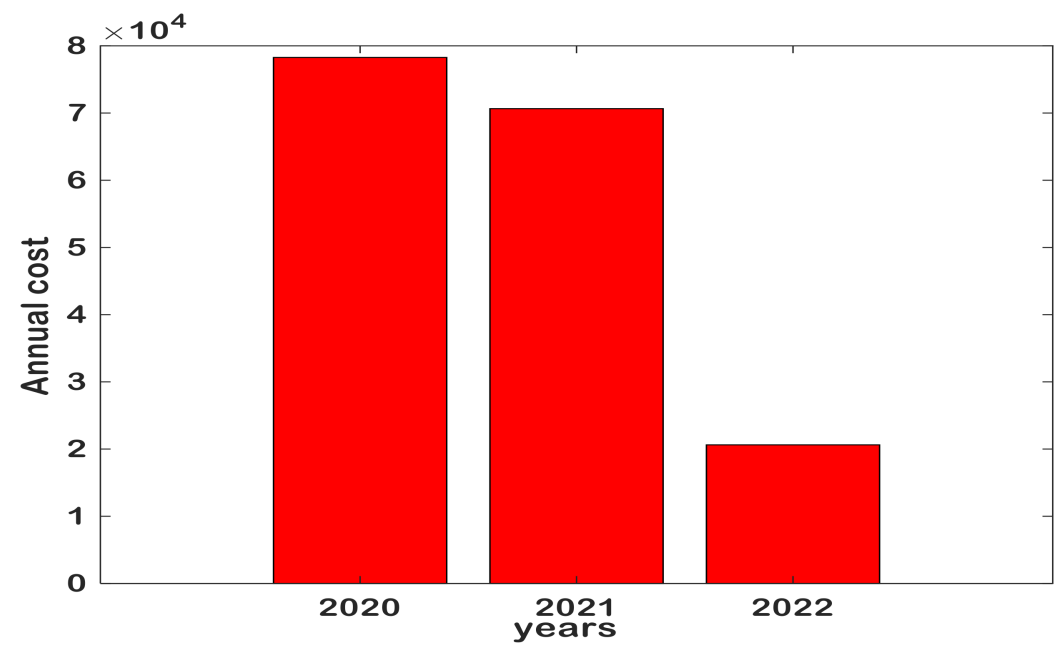

Figure 7. Annual maintenance cost during three years.

Table 5. Total annual PCR and its maintenance cost.

\begin{tabular}{cccccc}
\hline Year & $\boldsymbol{t}=\mathbf{0}$ & $\boldsymbol{t}=\mathbf{1}$ & $\boldsymbol{t}=\mathbf{2}$ & $\boldsymbol{t}=\mathbf{3}$ & Sum of $\boldsymbol{t}=\mathbf{1}, \mathbf{2 , \mathbf { 3 }}$ \\
\hline Total annual PCR & 60 & 128 & 166 & 176 & 470 \\
Average annual PCR & 1.22 & 2.61 & 3.39 & 3.59 & 9.59 \\
Annual cost (\$) & - & $78,272.06$ & $70,650.90$ & $20,623.38$ & $169,546.34$ \\
\hline
\end{tabular}

Furthermore, the effectiveness of the results is statistically analyzed using the range and standard deviation of the PCR of the maintained roads in each year as depicted in Figure 8. Where the standard deviation and PCR range are decreasing with the planned annual maintenance. Moreover, the ISA algorithm utilized the maintenance activity M-01 about $21 \%$, however, M-04 used rarely $~ 1 \%$ as depicted in Figure 9 . These results reveal that the pavement maintenance of case study can be done effectively with the lowest cost. In addition, Figure 10 shows that the maintenance activities are optimally distributed between road classes. For the arterial roads, M-01 is the most used maintenance activity, however M-04 is never used. For local access roads, all maintenance activities are used, where M-02 is mostly used. For the main roads, all maintenance activities are applied, where the M-01 is mostly used. These results prove the effectiveness of the proposed optimization method for lowest cost of pavement maintenance management. 


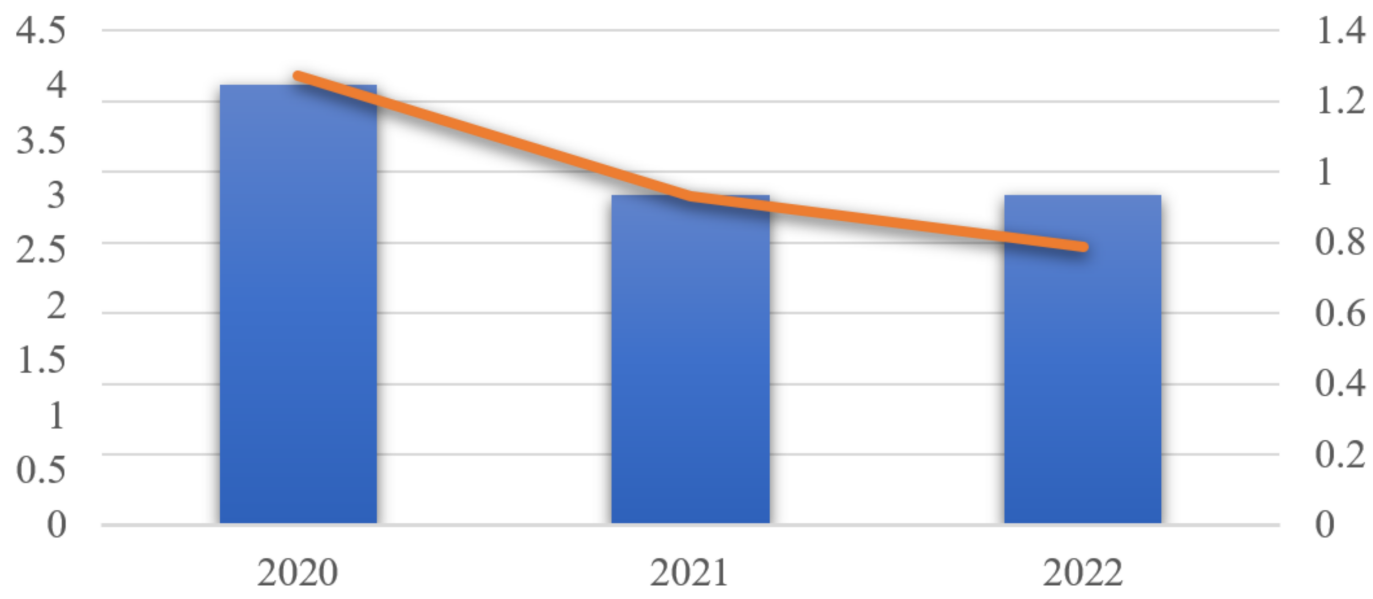

Figure 8. Range and standard deviation of PCR.

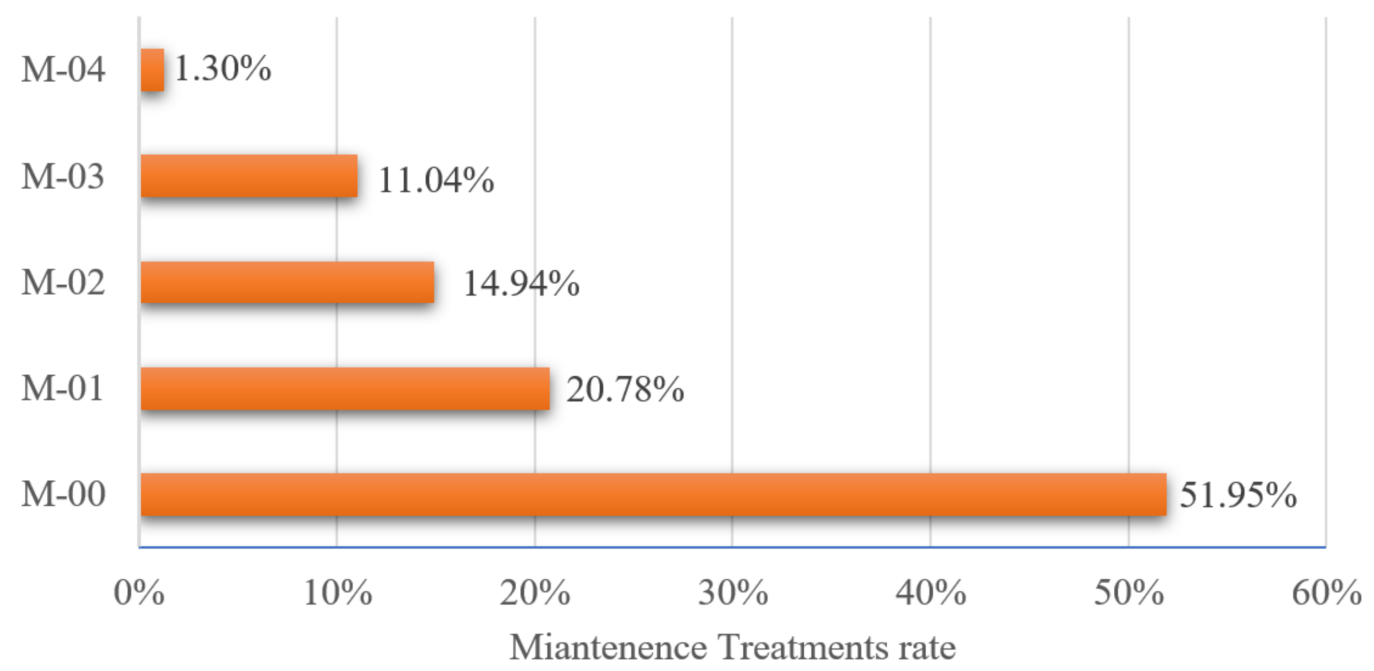

Figure 9. Optimal distribution of maintenance activities.

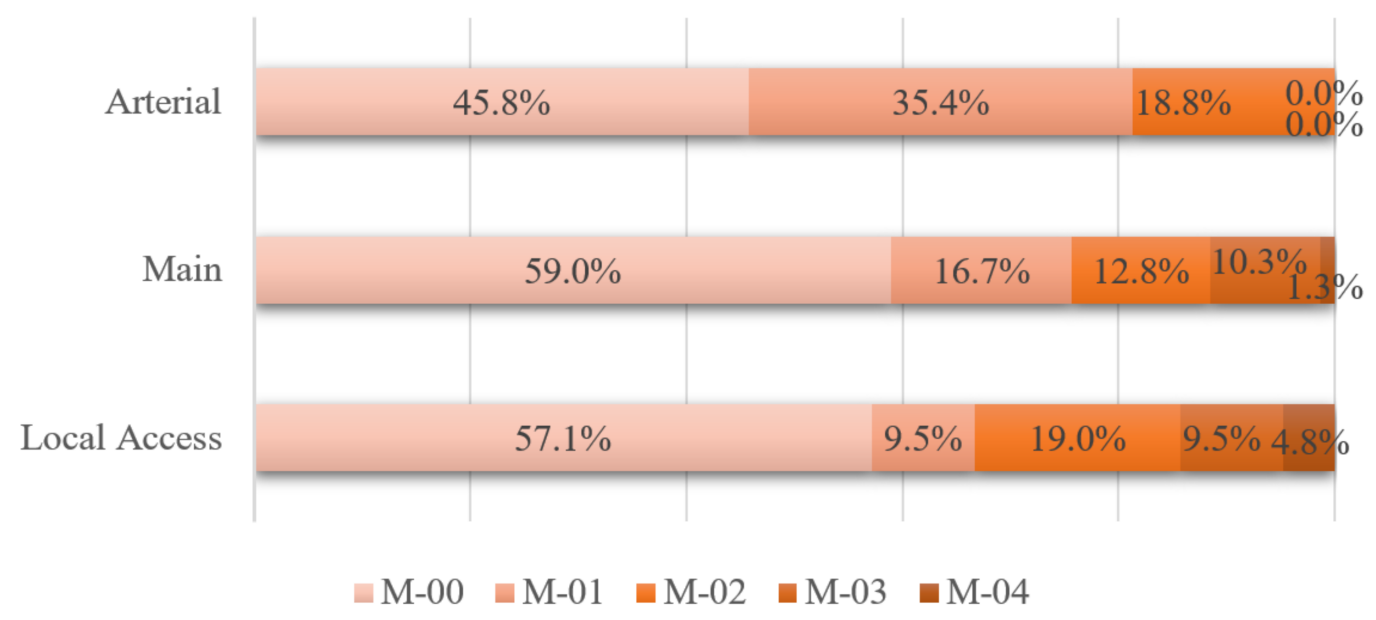

Figure 10. Optimal distribution of maintenance activities for road classes. 


\section{Conclusions}

This paper has proposed a new discrete multi-objective stochastic algorithm based on the stochastic integer numbers, which is called integer search algorithm (ISA). Then, the ISA algorithm is applied to solve the constrained multi-objective function (pavement maintenance management (PMMS)). The main objectives of the PMMS problem are maximizing the performance of road pavements and minimizing the maintenance cost and constrained by the annual budget. In this paper, the case study is selected for Hajjah city in Yemen (developing country), where the number of roads is 16, and the number of sections is 49. Therefore, the number of input and output variables of PMMS is 49. The ISA and GA algorithms are applied to maintain all road sections in three years, so the maintenance activities are distributed during these years to obtain minimum cost. The optimization results revealed that the ISA achieved higher total PCR and lower total cost than that achieved by the GA algorithm. Also, the results show that the PCR is increased to $193 \%$ of the initial PCR with $29 \%$ cost-savings.

Author Contributions: Conceptualization, A.A.; Funding acquisition, A.A.-M.; Investigation, M.Q.; Methodology, A.A.; Resources, A.A.-M.; Software, M.Q.; Supervision, A.A.-M. All authors have read and agreed to the published version of the manuscript.

Funding: This research received no external funding.

Institutional Review Board Statement: Not applicable.

Informed Consent Statement: Not applicable.

Data Availability Statement: Not applicable.

Acknowledgments: Authors acknowledge the research center of college of engineering at King Saud University for the financial support to carry out this research paper.

Conflicts of Interest: The authors declare no conflict of interest.

\section{References}

1. France-Mensah, J.; O’Brien, W.J. Developing a Sustainable Pavement Management Plan: Tradeoffs in Road Condition, User Costs, and Greenhouse Gas Emissions. J. Manag. Eng. 2019, 35, 04019005. [CrossRef]

2. Fwa, T.F.; Chan, W.T.; Hoque, K.Z. Multiobjective optimization for pavement maintenance programming. J. Transp. Eng. 2000, 126, 367-374. [CrossRef]

3. Wei, J.; Kong, Y.; Fu, Z. Multi-objective optimization for pavement maintenance and rehabilitation strategies. In Proceedings of the International Conference on Transportation Engineering 2009, Chengdu, China, 25-27 July 2009; pp. $2919-2924$.

4. Torres-Machi, C.; Pellicer, E.; Yepes, V.; Chamorro, A. Towards a sustainable optimization of pavement maintenance programs under budgetary restrictions. J. Clean. Prod. 2017, 148, 90-102. [CrossRef]

5. Konak, A.; Coit, D.W.; Smith, A.E. Multi-objective optimization using genetic algorithms: A tutorial. Reliab. Eng. Syst. Saf. 2006, 91, 992-1007. [CrossRef]

6. Abaza, K.A. Iterative linear approach for nonlinear nonhomogenous stochastic pavement management models. J. Transp. Eng. 2006, 132, 244-256. [CrossRef]

7. Butt, A.A.; Shahin, M.Y.; Carpenter, S.H.; Carnahan, J.V. Application of Markov process to pavement management systems at network level. In Proceedings of the 3rd International Conference on Managing Pavements, San Antonio, TX, USA, 22-26 May 1994; Volume 2, pp. 159-172.

8. $\mathrm{Wu}, \mathrm{Z}$; Flintsch, G.W.; Chowdhury, T. Hybrid multiobjective optimization model for regional pavement-preservation resource allocation. Transp. Res. Rec. 2008, 2084, 28-37. [CrossRef]

9. Durango-Cohen, P.L.; Sarutipand, P. Maintenance optimization for transportation systems with demand responsiveness. Transp. Res. Part C Emerg. Technol. 2009, 17, 337-348. [CrossRef]

10. Gu, W.; Ouyang, Y.; Madanat, S. Joint optimization of pavement maintenance and resurfacing planning. Transp. Res. Part B Methodol. 2012, 46, 511-519. [CrossRef]

11. Dissanayake, S.; John Lu, J.; Chu, X.; Turner, P. Use of multicriteria decision making to identify the critical highway safety needs of special population groups. Transp. Res. Rec. 1999, 1693, 13-17. [CrossRef]

12. Farhan, J.; Fwa, T.F. Incorporating priority preferences into pavement maintenance programming. J. Transp. Eng. 2012, 138, 714-722. [CrossRef]

13. Lambert, J.H.; Wu, Y.-J.; You, H.; Clarens, A.; Smith, B. Climate change influence on priority setting for transportation infrastructure assets. J. Infrastruct. Syst. 2013, 19, 36-46. [CrossRef] 
14. Gharaibeh, N.G.; Chiu, Y.-C.; Gurian, P.L. Decision methodology for allocating funds across transportation infrastructure assets. J. Infrastruct. Syst. 2006, 12, 1-9. [CrossRef]

15. Giustozzi, F.; Crispino, M.; Flintsch, G. Multi-attribute life cycle assessment of preventive maintenance treatments on road pavements for achieving environmental sustainability. Int. J. Life Cycle Assess. 2012, 17, 409-419. [CrossRef]

16. Li, Z.; Sinha, K.C. Methodology for multicriteria decision making in highway asset management. Transp. Res. Rec. 2004, 1885, 79-87. [CrossRef]

17. Farhan, J.; Fwa, T.F. Pavement maintenance prioritization using analytic hierarchy process. Transp. Res. Rec. 2009, 2093, 12-24. [CrossRef]

18. Šelih, J.; Kne, A.; Srdić, A.; Žura, M. Multiple-criteria decision support system in highway infrastructure management. Transport 2008, 23, 299-305. [CrossRef]

19. Shelton, J.; Medina, M. Integrated multiple-criteria decision-making method to prioritize transportation projects. Transp. Res. Rec. 2010, 2174, 51-57. [CrossRef]

20. Sun, L.; Gu, W. Pavement condition assessment using fuzzy logic theory and analytic hierarchy process. J. Transp. Eng. 2011, 137, 648-655. [CrossRef]

21. Chan, W.T.; Fwa, T.F.; Tan, J.Y. Optimal fund-allocation analysis for multidistrict highway agencies. J. Infrastruct. Syst. 2003, 9, 167-175. [CrossRef]

22. Chootinan, P.; Chen, A.; Horrocks, M.R.; Bolling, D. A multi-year pavement maintenance program using a stochastic simulationbased genetic algorithm approach. Transp. Res. Part A Policy Pract. 2006, 40, 725-743. [CrossRef]

23. Mathew, B.S.; Isaac, K.P. Optimisation of maintenance strategy for rural road network using genetic algorithm. Int. J. Pavement Eng. 2014, 15, 352-360. [CrossRef]

24. Morcous, G.; Lounis, Z. Maintenance optimization of infrastructure networks using genetic algorithms. Autom. Constr. 2005, 14, 129-142. [CrossRef]

25. Pilson, C.; Hudson, W.R.; Anderson, V. Multiobjective optimization in pavement management by using genetic algorithms and efficient surfaces. Transp. Res. Rec. 1999, 1655, 42-48. [CrossRef]

26. Santos, J.; Ferreira, A.; Flintsch, G. An adaptive hybrid genetic algorithm for pavement management. Int. J. Pavement Eng. 2019, 20, 266-286. [CrossRef]

27. Shen, Y.; Bu, Y.; Yuan, M. A novel chaos particle swarm optimization (PSO) and its application in pavement maintance decision. In Proceedings of the 2009 4th IEEE Conference on Industrial Electronics and Applications, Xi'an, China, 25-27 May 2009; pp. 3521-3526.

28. Tayebi, N.R.; Moghadasnejhad, F.; Hassani, A. Analysis of pavement management activities programming by particle swarm optimization. In Proceedings of the International Conference on Advances in Electrical \& Electronics, Trivandrum, Kerala, India, 1 January 2010; pp. 149-154.

29. Mahmood, M.; Mathavan, S.; Rahman, M. A parameter-free discrete particle swarm algorithm and its application to multiobjective pavement maintenance schemes. Swarm Evol. Comput. 2018, 43, 69-87. [CrossRef]

30. Greco, S.; Matarazzo, B.; Słowiński, R. Dominance-based rough set approach to interactive multiobjective optimization. In Multiobjective Optimization; Springer: London, UK, 2008; pp. 121-155.

31. Augeri, M.G.; Colombrita, R.; Greco, S.; Lo Certo, A.; Matarazzo, B.; Slowinski, R. Dominance-based rough set approach to budget allocation in highway maintenance activities. J. Infrastruct. Syst. 2011, 17, 75-85. [CrossRef]

32. Augeri, M.G.; Greco, S.; Nicolosi, V. Planning urban pavement maintenance by a new interactive multiobjective optimization approach. Eur. Transp. Res. Rev. 2019, 11, 17. [CrossRef]

33. Zhao, M.; Chen, Z.; Blaabjerg, F. Optimisation of electrical system for offshore wind farms via genetic algorithm. IET Renew. Power Gener. 2009, 3, 205-216. [CrossRef]

34. Shin, H.-U.; Lee, K.-B. Optimal design of a $1 \mathrm{~kW}$ switched reluctance generator for wind power systems using a genetic algorithm. IET Electr. Power Appl. 2016, 10, 807-817. [CrossRef] 